\title{
Learning Strabismus Surgery: A Case-Based Approach Eds: Cestari D, Hunter D G, Associate Eds: Heidary G, Nihalani BR, Wong RK (2013), ISBN: 978-1-4511-1660-1. Lippincott Williams \& Wilkins
}

\author{
Daniel Mojon
}

Received: 20 June 2014 / Accepted: 25 June 2014 / Published online: 12 July 2014

(C) Springer-Verlag Berlin Heidelberg 2014

The book "Learning Strabismus Surgery: A Case-Based Approach" targets the novice student as well as the experienced strabismus surgeon by selecting 52 cases covering different levels of difficulty. The cases cover the majority of topics in squint surgery. The authors reproduce the kind of learning that occurs during a 1-year fellowship with strabismus experts. Thus, they suggest studying one case every week.

The editors, Dean Cestari and David Hunger from Boston, are both well-known excellent strabismus surgeons and teachers. The language is English.

Many cases are presented in the following way: history, examination, assessment/plan, surgery including videos, postoperative assessment, follow-up, review/lessons learned and references. A table at the beginning of the book includes for each case the diagnosis, the type of procedures, the clinical features, and which exact surgery has been performed. This allows readers to quickly find a case similar to one of their own patients. The appendix includes strabismus surgery tables and photos of instruments and figures illustrating adjustable suture techniques. Many cases cover topics hardly found in other squint surgery books, such as V-esotropia after LASIK, restrictive strabismus after pterygium surgery, strabismus following ruptured globe, chronic progressive external ophthalmoplegia, and strabismus after bilateral scleral buckle repair.

The book and a total of 20 videos with durations from half a minute to 15 min can be accessed with the access code included in each book. The whole book includes goodquality full-colour photographic images, diagrams, and references for each case. The information provided in the book is relevant to ophthalmology residents and general ophthalmologists as well as the experienced strabismus surgeon. The presentation of real clinical cases makes the information easy to digest.

In summary, this book can be highly recommended to anyone interested in squint surgery.
D. Mojon $(\bowtie)$

Airport Medical Center Eye Clinic, Prime Center 1, PO Box 2128, CH-8060Zurich Airport, Zurich, Switzerland

e-mail: daniel.mojon@gmail.com 